\title{
Re-Evaluation of the Haptoglobin Reference Values with the Radial Immunodiffusion Technique
}

\author{
JAAP SCHRIJVER, ${ }^{1}$ HERMAN J. M. VAN RIJN, ${ }^{2}$ and WIL H. P. SCHREURS ${ }^{1}$ \\ 'Department of Clinical Biochemistry, Institute CIVO-Toxicology \& Nutrition TNO, Zeist, \\ The Netherlands \\ and
}

${ }^{2}$ Clinical and Hematological Laboratory, Dr. A. Mathijsen Hospital, Utrecht, The Netherlands

\begin{abstract}
The reference values of the three main types of serum haptoglobin $\mathrm{Hp} 1-1, \mathrm{Hp} 2-1$, and $\mathrm{Hp} 2-2$, as determined by radial immunodiffusion and with phenotype determination on polyacrylamide gel electrophoresis have been re-evaluated for both sexes. For that purpose about 500 serum samples were collected from normal, healthy Dutch volunteers. The relative occurrence of the three main types of serum haptoglobin in Dutch men and women was found to be comparable to that reported for other whites, with the $\mathrm{Hp} 2-1$ phenotype predominating in the Dutch population and phenotype $\mathrm{Hp} 0-0$ being absent. The observed overall reference range of haptoglobin for the Dutch population, irrespective of the phenotype, was $0.50-3.30 \mathrm{~g} / \mathrm{L}$ serum

As reported by other investigators we found that the reference values for the three main types of haptoglobin significantly differed

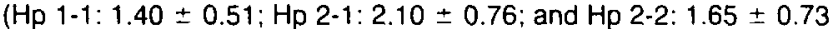
$g / L$ serum, mean $\pm S D$ ).

However, in contrast to the data available in the literature, the reference values of haptoglobin for men and for women, as determined by the radial immunodiffusion technique, were not significantly different.
\end{abstract}

KEY WORDS: haptoglobin, phenotypes, serum, radial immunodiffusion, reference values, sex differences

\section{Introduction}

$\mathrm{H}$ aptoglobins, first described in 1938 (1), are mucoproteins of the $\alpha_{2}$ globulin class, capable of interacting with hemoglobin or globin to form stable complexes. Heterogeneity exists within the haptoglobins, which is genetically controlled by the presence of two allelic autosomal genes, $\mathrm{Hp}^{1}$ and $\mathrm{Hp}^{2}(2)$. Three main types of haptoglobins are found in human populations (3), which have been designated as haptoglobins 1-1, 2-1 and 2-2. They can be distinguished from one another by the patterns they give in gel electrophoresis. There are multiple subtypes of haptoglobin. Furthermore, a third gene of type $0\left(\mathrm{Hp}^{\circ}\right)$ has been postulated to account for the complete absence of haptoglobin in

Correspondence: J. Schrijver, Institute CIVO-Toxicology and Nutrition TNO, Department of Clinical Biochemistry, P.O. Box 360, 3700 AJ ZEIST, The Netherlands.

Manuscript received September 27, 1983; revised manuscript received February 1, 1984; accepted for publication February 8, 1984. some population groups (4-6).

Haptoglobins prevent the build-up of free hemoglobin in plasma by binding the quantity released from the red cells, thereby preventing loss of iron via the kidney (7).

Haptoglobin levels are frequently elevated in inflammatory diseases, carcinoma and tissue necrosis. Elevated levels are sometimes found in diabetes mellitus, renal disease and endocrine imbalance. Depressed levels are found following episodes of intravascular hemolysis, in anemia, malaria, liver disease, and in mononucleosis and as a result of transfusion of incompatible blood. Nyman (8) has published an extensive review of the clinical aspects of haptoglobins.

The available methods to estimate haptoglobin in serum can be divided into several groups, viz. (a) measurement of the peroxidase activity of the haptoglobinhemoglobin complex, (b) electrophoresis of haptoglobin and the complex, (c) gel filtration, (d) immunodiffusion, (e) differential acid denaturation of hemoglobin and the complex, followed by spectrophotometry, and (f) immunonephelometry.

In recent years, more and more laboratories have come to rely upon immunological techniques for the estimation of haptoglobin. Of these techniques single radial immunodiffusion is a technically simple method measuring directly the haptoglobin concentration $(9-12)$. In this technique the square of the diameter of the ring of the immunoprecipitate, which is formed during the diffusion of the protein, is proportional to the concentration of the antigen haptoglobin. As the haptoglobin phenotypes have distinctly different molecular weights and therefore different diffusion rates, the immunochemical determination of haptoglobin is phenotype-dependent (13). It has also been reported that on the average males have significantly higher levels of serum haptoglobin than females (8). This difference should be consistent with the fact that males tend to have a greater mass of circulating hemoglobin (14). The influence of the phenotype in the quantitative determination of haptoglobin with the radial immunodiffusion technique and the different average value for both sexes prompted us to determine reference values. To our knowledge these values, determined with the Mancini technique (9) have not yet been presented for the three main types $\mathrm{Hp} \mathrm{1-1,} \mathrm{Hp} \mathrm{2-1} \mathrm{and} \mathrm{Hp} \mathrm{2-2}$ with respect to the two sexes. 


\section{Material and methods}

\section{REAGENTS AND EQUIPMENT}

Disc electrophoresis was performed by Desaga System Havana (C. Desaga GmbH, FRG) on vertical polyacrylamide gels (PAGE). Acrylamide was obtained from Serva (Heidelberg, FRG), and recrystallized from chloroform. $N, N^{\prime}$-methylenebisacrylamide and $N, N, N^{\prime}, N^{\prime}$-tetra-methylenediamine were purchased from Eastman Kodak Co. (Rochester, NY, USA).

All other chemicals were of analytical grade and were obtained from E. Merck AG (Darmstadt, FRG) or JT Baker Chemicals (Deventer, The Netherlands).

\section{Methods}

For the radial immunodiffusion technique, commercially prepared immunodiffusion plates (M-Partigen ") and human protein standard serum $B$ (cat. no. RDT 02) were obtained from Behringwerke AG (Marburg/Lahn, FRG). The plates contain monospecific polyvalent antiserum, produced by immunizing rabbits with purified human haptoglobins.

The human protein standard serum B consists of three standard solutions with different haptoglobin concentrations. These standards were run on every immunodiffusion plate together with the unknown samples. A control serum sample was regularly used for quality control. A diffusion time of $48 \mathrm{~h}$ was allowed at room temperature, after which time a sharply confined precipitin ring of the antigen-antibody complex was obtained.

The concentration of haptoglobin in the unknown samples was read from a calibration curve in which the square of the diameter of the precipitin ring was plotted against the haptoglobin concentration using the standard solutions as references. The haptoglobin concentrations obtained in this way are relative amounts. In the radial immunodiffusion technique the variation in size of the antigen protein molecule (different phenotypes) causes the diffusion coefficient and hence the size of the precipitin ring to vary (9). This should be compensated for by the factors given by the manufacturer of the plates.

These factors are determined empirically. For the plates used in our study these factors were 0.6 (type 1-1), 1.3 (type 2-1) and 1.5 (type 2-2) respectively, according to Behringwerke AG. The present technique is limited by the need to rely on these factors and to determine the phenotype before an accurate value can be given (13).

The haptoglobin phenotypes were determined by disc-PAGE, with the method of Smith et al. (15), except that $7.5 \%$ instead of $5 \%$ gel was used.

After electrophoresis the gels were placed overnight in a $1 \mathrm{~g} / \mathrm{L}$ solution of human hemoglobin in $9 \mathrm{~g} / \mathrm{L} \mathrm{NaCl}$. The hemoglobin bound to haptoglobin in the gel was stained by incubation at room temperature in a freshly prepared solution of $o$-dianisidine $(1.05 \mathrm{~g} / \mathrm{L})$ in $0.15 \mathrm{M}$ acetate buffer $(\mathrm{pH} 4.7)$, containing $0.2 \mathrm{~mL} 30 \%(\mathrm{v} / \mathrm{v})$ $\mathrm{H}_{2} \mathrm{O}_{2}$ per $100 \mathrm{~mL}$. The gels were allowed to stay in the staining solution until brown bands were clearly vis-

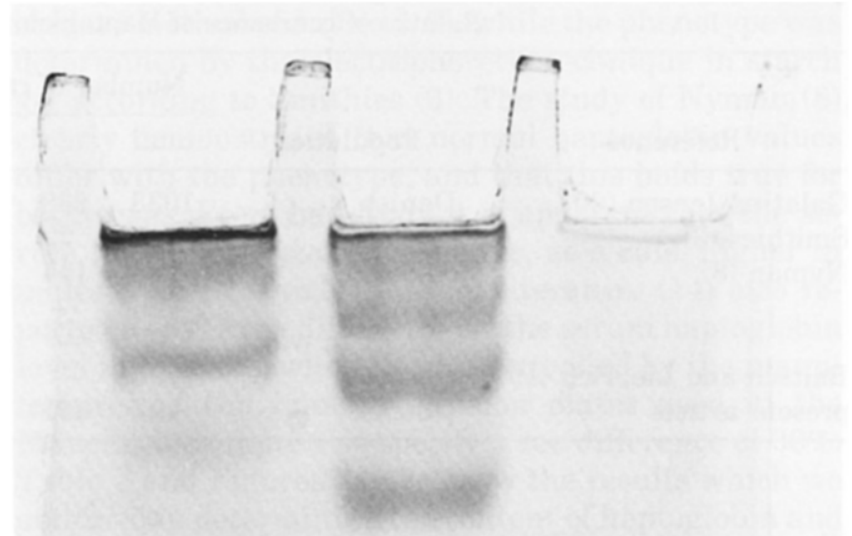

Figure $1-$ The banding patterns of the three main types of haptoglobin as observed on PAGE. From left to right: type 2-2, type 2-1 and type 1-1.

ible (20-30 $\mathrm{min}$ ) and were then removed and washed with distilled water. A large number of very sharp bands were obtained which, however, in spite of their adequate resolution, were sometimes difficult to identify, due to the low concentration of haptoglobin. The number of bands with their travelling distances is specific to the haptoglobin phenotype (16). An example of the banding patterns of the three main types of haptoglobin seen in our study is shown in Figure 1.

\section{SAMPLES}

Sera were prepared from blood samples collected from veins of normal, healthy Dutch volunteers of both sexes (age: 18 to 65 years) directly into "Venoject evacuated tubes" (Terumo Co., Tokyo, Japan). Volunteers 
SCHRIJVER, VAN RIJN, AND SCHREURS

TABLE 1

Relative Occurrence of Haptoglobin-Types in Different White Populations

\begin{tabular}{|c|c|c|c|c|c|c|c|c|c|c|c|c|c|c|}
\hline \multirow[b]{2}{*}{ Reference } & \multirow[b]{2}{*}{ Population } & \multicolumn{3}{|c|}{ Number of cases } & \multicolumn{3}{|c|}{ Type 1-1\% } & \multicolumn{3}{|c|}{ Type $2-1 \%$} & \multicolumn{3}{|c|}{ Type $2-2 \%$} & \multirow[b]{2}{*}{ Type $0-0 \%$} \\
\hline & & total & $\delta$ & q & total & $\dot{0}$ & \& & total & $\dot{0}$ & Q & total & $\delta$ & 9 & \\
\hline Galatius-Jensen (20) & Danish & 1033 & 238 & 795 & 17 & 17 & 17 & 47 & 47 & 47 & 36 & 36 & 36 & 0 \\
\hline Smithies (3) & Canadian & 49 & 22 & 27 & 21 & 31 & 11 & 50 & 45 & 55 & 29 & 22 & 33 & 0 \\
\hline \multirow{3}{*}{ Nyman (8) } & Swedish & 228 & 144 & 84 & 21 & 15 & 28 & 47 & 47 & 35 & 32 & 38 & 37 & 0 \\
\hline & French & 406 & - & - & 15 & 一 & - & 50 & - & - & 35 & - & - & 0 \\
\hline & American white & 68 & - & - & 13 & - & - & 59 & - & - & 28 & - & - & 0 \\
\hline \multirow{2}{*}{$\begin{array}{l}\text { Baitsch and Liebrich (19) } \\
\text { present article }\end{array}$} & German & 700 & - & - & 19 & - & - & 51 & - & 一 & 30 & - & - & 0 \\
\hline & Dutch & 497 & 268 & 229 & 20 & 16 & 24 & 48 & 51 & 46 & 32 & 33 & 30 & 0 \\
\hline
\end{tabular}
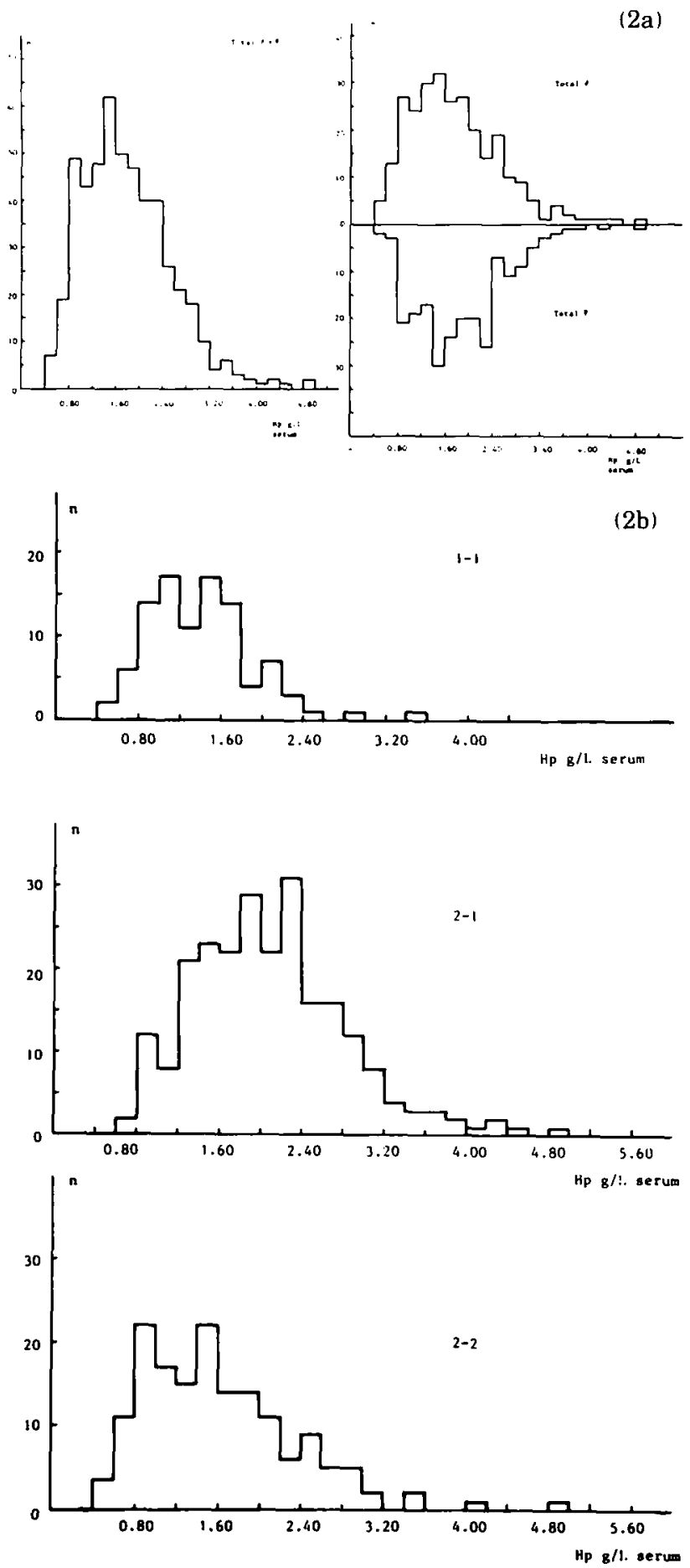
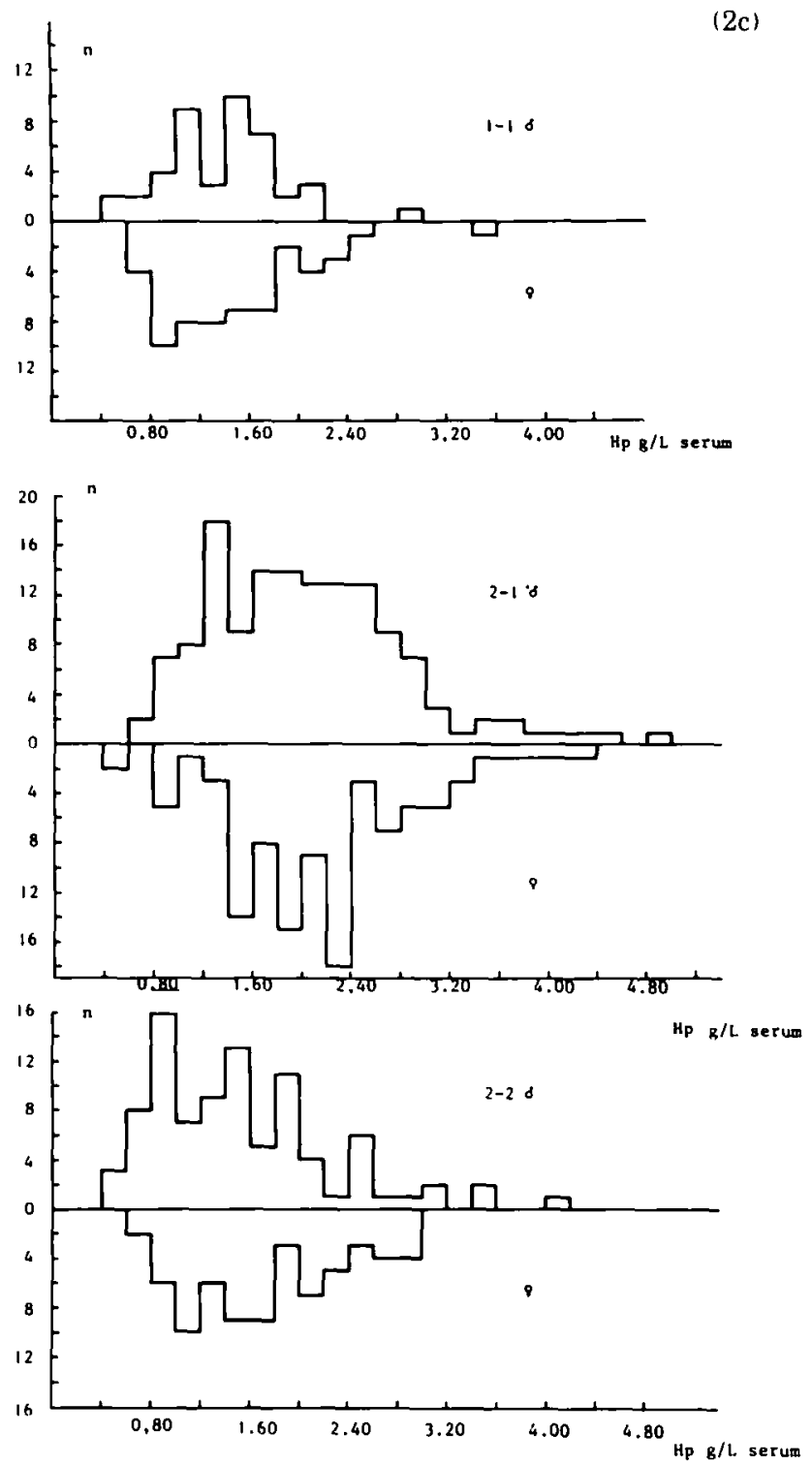

Figures 2a, 2b, 2c - Distribution of haptoglobin values before and after classification according to Hp-type and to sex. (2a) Left half of figure indicates frequency distribution of Hp values in sera from 497 healthy Dutch adults before classification by sex; right half indicates distribution after classification. (2b) Figure $2 b$ shows frequency distribution of $\mathrm{Hp}$ values by Haptoglobin Type before classification. (2c) Figure 2c shows frequency distribution of $\mathrm{Hp}$ values by $\mathrm{Hp}$ Type after classification. 
TABLE 2

Reference Values for and Relative Occurrence of Haptoglobin Types in the Dutch Population

\begin{tabular}{lcrrccl}
\hline & $\begin{array}{c}\text { Hp } \\
\text { type }\end{array}$ & $n$ & $\%$ & Mean & SD & $\begin{array}{c}\text { Reference } \\
\text { Range }\end{array}$ \\
\hline Total & - & 497 & 100 & 1.59 & 0.76 & $0.50-3.30^{2}$ \\
& $1-1$ & 98 & 20 & 1.40 & 0.51 & $0.70-2.30$ \\
& $2-1$ & 239 & 48 & 2.10 & 0.76 & $0.90-3.60$ \\
& $2-2$ & 160 & 32 & 1.65 & 0.73 & $0.60-2.90$ \\
Men & - & 268 & 100 & 1.51 & 0.75 & $0.50-3.00^{2}$ \\
& $1-1$ & 43 & 16 & 1.39 & 0.46 & $0.80-2.10$ \\
& $2-1$ & 137 & 51 & 2.06 & 0.79 & $0.90-3.60$ \\
Women & $2-2$ & 88 & 33 & 1.56 & 0.74 & $0.60-2.60$ \\
& $1-1$ & 229 & 100 & 1.68 & 077 & $0.60-3.30^{2}$ \\
& $2-1$ & 105 & 46 & 2.13 & 0.92 & $0.90-3.40$ \\
& $2-2$ & 69 & 30 & 1.76 & 0.73 & $0.70-2.90$ \\
\hline
\end{tabular}

'Values are given in $\mathrm{g} / \mathrm{L}$ serum.

"Values as calculated directly from the immunoprecipitin ring (untyped). The conversion factors were 0.6 for type 1-1, 1.3 for type $2-1$ and 1.5 for type $2-2$ respectively, in accordance with the information of the manufacturer.

were selected who had normal renal function and absence of metabolic and hematological disease.

For the assessment of the reference values of haptoglobin the distribution-free method described by Rümke and Bezemer (17) was used. The limits of percentiles were set at 2.5 and $97.5 \%$ with a reliability of $95 \%$.

\section{Results and discussion}

\section{Phenotype Distribution}

A number of papers have been published on the relative occurrence of haptoglobin groups within different populations (for reviews see refs. 8 and 18). For example, $\mathrm{Hp}^{1}$ predominates in the populations of Africa and tropical America, but is seldom encountered in Asia (19).

The haptoglobin phenotype 1-1 is more common among coloured people; in Europe phenotype $2-1$ is found in at least $40 \%$ of the population, while in Asia phenotype 2-2 predominates.

In Table 1 the percentage of haptoglobin types observed in our group are given and compared to those reported for other whites. The distribution of the three phenotypes in the Dutch population seems not to diverge from that in other white populations. Also, in our group no type $0-0$ has been observed. It is concluded that the results presented in this paper are representative of other whites. Perhaps with the exception of type $1-1$, there seems to be no difference between Dutch males and females (cf. the Danish group, Table 1) regarding the relative occurrence of the haptoglobin phenotypes.

\section{REFERENCE VALUES}

Nyman (8) was the first (1959) to report extensively on normal values of haptoglobin. She determined the hemoglobin-binding capacity of serum by the peroxidase method of Jayle $(1,2)$, while the phenotype was determined by the electrophoretic technique in starch gel according to Smithies (3). The study of Nyman (8) clearly demonstrated that normal haptoglobin values differ with the phenotype, and that this holds true for both sexes. From her study it is apparent that the serum haptoglobin concentration is, as a rule, higher in males than in females. Recent literature (14) also reported a $(30 \%)$ sex difference for the serum haptoglobin level in humans, while the data supplied by the manufacturer of the immunodiffusion plates used in the Mancini technique also specify a sex difference of $30 \%$. Table 2 and Figures $2 a-2 c$ show the results which we obtained in determining the content of haptoglobin and its different phenotypes in Dutch volunteers by the single radial immunodiffusion technique (9) and discPAGE (15).

The haptoglobin values are given as the relative amount, calculated directly from the size of the precipitin ring of the M-Partigen" plates, using the human protein standard serum $B$ as the reference, and also as the concentrations of the specific phenotypes of haptoglobin.

The precision of the determination of the relative amount of haptoglobin in serum was obtained by assaying one and the same serum sample on consecutive days. A coefficient of variation of $6.25 \%$ for the between-assay was obtained at a relative haptoglobin concentration of $1.12 \pm 0.07 \mathrm{~g} / \mathrm{L}$ (mean $\pm \mathrm{SD}, n=33$ ). In agreement with the results of Nyman (8) and others (10 and 11), Table 2 shows that reference values of haptoglobin are phenotype-dependent. Furthermore, Figure 1 indicates that the frequency distribution of the overall reference material ( 497 samples) as well as that of men (268) and women (229) are not Gaussian, irrespective of the phenotype.

However, in contrast with the study of Nyman (8) on the hemoglobin-binding capacity, our results show that the serum haptoglobin concentration of males is not higher than that of females, in fact it is lower if anything. As a general rule it can be stated that haptoglobin levels of the two sexes as determined by radial immunodiffusion do not differ. To our knowledge this observation has not been presented earlier in such clear-cut form by giving frequency distributions, means, SD's and reference ranges in normal sera of both sexes. As the method and plates applied in this study are quite common in clinical laboratories, one can imagine that haptoglobin reference values incorporating a difference of about $30 \%$ between male and female values, are widely used.

\section{References}

1. Polonowski M, Jayle MF. Existence dans le plasma sanguin d'une substance activant l'action peroxydasique de l'hémoglobine. CR Soc Biol (Paris) 1938; 129: 457-62.

2. Jayle MF, Moretti J. Haptoglobin: Biochemical, genetic and physiopathologic aspects. Progr Hematol 1962; 3: 342-59.

3. Smithies O. Zone electrophoresis in starch gels: group variations in the serum proteins of normal human adults. Biochem $J$ 1955; 5: 629-41. 
4. Giblett ER. The haptoglobin system. Ser Haematol 1968; 1: $3-21$.

5. Javid J. Human haptoglobins. Curr Top Hemat 1978; 1: 151-92.

6. Putnam FW. The Plasma Proteins: Structure, function and genetic control. Vol II, Pp. 1-50. New York: Academic Press, 1975.

7. Allison AC. The genetical and clinical significance of the haptoglobins. Proc $R$ Soc Med 1958; 51: 641-5.

8. Nyman M. Serum haptoglobin. Methodological and clinical studies. Scand J Clin Lab Invest 1959; 11. Suppl. 39.

9. Mancini G, Carbonara AO, Heremans JF. Immunochemical quantitation of antigens by single radial immunodiffusion. Immunochemistry 1965; 2: 235-54.

10. Braun HJ, Aly FW. Problems in the quantitative estimation of human serum haptoglobin by single radial immunodiffusion. Clin Chim Acta 1969; 26: 588-90.

11. Douma GJ, Van Dalen A. An evaluation of the diagnostic value of haptoglobin and transferrin levels in serum. $Z$. Klin Chem Klin Biochem 1974; 12: 474-6.

12. Van Lente F, Marchand A, Galen RS. Evaluation of a nephelometric assay for haptoglobin and its clinical usefulness. Clin Chem 1979; 25: 2007-10.

13. Valette I, Pointis J, Rondeau Y, Waks M, Engler R.
Is immunochemical determination of haptoglobin phenotype-dependent? Clin Chim Acta 1979; 99: 1-6.

14. Peters Jr. Th. In: Brown SS, Mitchell FL, Young WS Eds. Chemical Diagnosis of Disease. Pp. 311-62. Amsterdam: Elsevier/North Holland, 1979.

15. Smith I, Lightstone PJ, Perry JD. Separation of human tissue alkaline phosphatases by electrophoresis on acrylamide disc gels. Clin Chim Acta 1968: 19: 499-505.

16. Engler R, Rondeau Y, Pointis J, Jayle MF. Activités peroxydasiques des combinaisons hémoglobiniques des trois phénotypes de l'haptoglobine. Clin Chim Acta 1973; 47: $149-52$.

17. Rümke Chr. L, Bezemer PD. Methoden voor de bepaling van normale waarden. II: Nieuwe methoden. Ned Tijdschr Geneeskd 1972; 116: 1559-68.

18. Prokop O, Uhlenbruch $G$. Lehrbuch der menschlichen Blut- und Serumgruppen. VEB Thieme Verlag, Leipzig (1963) Pp. 430-5.

19. Baitsch H, Liebrich KG. Haptoglobin types. Method of determination: Allele incidences in some random samples. Blut 1961: 7: 27-37.

20. Galatius-Jensen F. Further investigations of the genetic mechanism of the haptoglobins. Acta Genet 1957; 7: $549-64$. 